\title{
Prediction of college grades in the sample of Norwegian students
}

\author{
Kovač, Velibor Bobo ${ }^{a}$;Vikstøl Olsen ${ }^{a}$, Anne Karin ${ }^{a}$; Spieler, Kristin ${ }^{\text {a }}$ \\ ${ }^{\mathrm{a}}$ Department of Education, University of Agder, Kristiansand, Norway.
}

\begin{abstract}
In the present study we examine the relative impact of individual variables (school attendance, student learning efficacy, and behavioural intentions) and learning environment (LE; perceived justice, social identification, learning context, and organizational citizenship behaviour) on student grades. Participants comprised 201 students enrolled in a mid-size university in Norway. The individual predictors explained $30 \%$ of the variance in actual grades, with self-efficacy beliefs, non-mandatory school attendance, intentions to get a specific grade, and intentions to quit studying as significant predictors. The LE variables explained zero \% (0\%) of the variance in actual grades. None of the included LE variables emerged as significant in the final step of the regression analysis. The central point in the discussion is dedicated to the somewhat surprising finding that none of the LE variables contributed to explained variance in actual grades.
\end{abstract}

Keywords: college grades, individual variables, learning environment. 


\section{Introduction}

The relationship between plausible theoretical candidates and academic achievements represents a well-explored area of research (see Richardson, Abraham, \& Bond, 2012 for a meta-analytic review). Reviewing this research, it is possible to argue that there exist two different levels of analysis concerning this topic. The first one focuses on the learner's individual characteristics in terms of cognitions, motivations, and behavior and the way these dispositions influence learning outcomes (Harackiewicz, Barron, Tauer, \& Elliot, 2002). The second approach emphasizes contextual aspects of learning environments and tend to focus on variables, such as organizational- and learning climate, and relationships among learners (Samdal, Wold, \& Bronis, 1999). Pursuing the aim of adopting a broader theoretical approach, in the present study we simultaneously examine the relative impact of of (1) individual variables and (2) learning environment (LE) on student grades.

\subsection{Individual variables}

Individual variables included in our study refer to personal dispositions that are in lesser degree related to contextual influences that are embedded in the given learning environment. The first individual variable is school attendance that is in current literature frequently positively associated with academic achievements (Credé, Roch, \& Kieszczynka, 2010). The measure of school attendance in the present study is based on selfreported attendance in terms of automatic or habitual processes (Verplanken \& Orbell, 2003). In addition to the measure of habitual school attendance we have also included an item that measures the degree in which students attend non-mandatory lectures. The second individual variable refers to self-efficacy beliefs and the quantity of time invested in doing required academic tasks. The positive effects of academic self-efficacy on academic achievements are well-documented (Sharma \& Silbereisen, 2007). In addition, we also measure the quantity of time students invest in school work considering that concept of self-efficacy beliefs does not necessarily reflect efforts invested. The third individual variable refers to intentions to get a specific grade and intentions to quit studying. The concept of intention is in contemporary literature frequently identified as the most important determinant of volitional behavior (Ajzen, 1991). In addition, we also included a measure of intention to quit studying in order to capture motivational struggle to complete studies. 


\subsection{LE variables}

The learning environment (LE) variables refer to processes that are to a higher degree associated with contextual influences. The first LE variable is perceived justice which refers to expressed perceptions about the extent to which people are treated fairly in given settings (Greenberg, 2010). According to Blader and Tyler (2005) perception of fairness have a vital impact on behavioral performance. The second LE variable refers to two different aspects of social identification. The first aspect, occupational identity, refers to the student's conscious awareness of oneself as a kindergarten teacher in terms of internalizing knowledge, skills, attitudes, and values that are characteristics of members of the profession. The second aspect of social identity is associated with the student's relation to their class in the kindergarten teacher education (Furrer \& Skinner, 2003). The third LE variable refers to learning climate and basic learning orientations that characterize most learning. In the present study, we measure mastery orientation that characterized student learning context in form of stimulation of intrinsic motivation and general class support. And finally, we also included the measure of Organizational citizenship behavior (OCB) that consists of 3 conceptually distinct dimensions (Podsakoff, Ahearne, \& MacKenzie, 1997): sportsmanship (the willingness to tolerate the inevitable inconveniences), civic virtue (constructive involvement in the organization), and helping behavior (voluntarily helping others). Previous research found positive association between OCB and academic achievement (Allison, Voss, \& Dryer, 2001).

\subsection{Dependent variable: academic achievements as measured in grades}

Actual grades were assessed by obtaining registered exam results directly from the university office of student records. The Norwegian system of grading in higher education is a letter-grade system ranging from $\mathrm{F}$ ( $\mathrm{F}=1$, non-passing) to $\mathrm{A}$ ( $\mathrm{A}=6$, highest possible). These letters were converted to a point system (1 to 6), respectively.

\subsection{Hypotheses}

To summarize, we sought to test the following hypotheses:

1. We hypothesize that academic achievements as measured in grades are significantly predicted by individual variables.

2. We hypothesize that academic achievements as measured in grades are significantly predicted by LE variables.

3. We hypothesize that individual variables are better predictors of academic achievements as measured in grades, compared to LE variables. 


\section{Method}

\subsection{Data collection and participants}

Participants comprised 201 university students enrolled in a mid-size university in Norway. The data was collected over a two-week period by asking students to complete the questionnaire prior to lectures in classrooms. In the previously provided cover letter, we asked participants to report their student number. The students were also explicitly informed that they could fill out the questionnaire without filling in the student number if they did not have it available. At the end of the semester (approximately four months after data collection), we gave the list of student numbers to the administrative office. This office provided us with the grades for each participant. The procedure was in advance approved by the university and the Norwegian Social Science Data Services (NSD). Instruments in the study consisted of self-reported measures that had been used in previous research with a similar purpose (Kovač, Cameron, \& Høigaard, 2016). The reference to instruments that were used could be found in the introduction part as attached to each individual and the LE variable.

\section{Results}

\subsection{Predicting actual grades with individual variables}

We performed a hierarchical regression analysis in which actual grades were regressed on planning (step 1), self-efficacy beliefs and the quantity of time invested in doing required academic tasks (step 2), habitual school attendance (step 3), non-mandatory school attendance (step 4), intentions to get a specific grade and intentions to quit studying (step 5 ). In the final regression equation, the predictors under consideration explained $30 \%$ of the variance in actual grades, with self-efficacy beliefs $(\beta=.16, p<.05)$, non-mandatory school attendance $(\beta=.25, \mathrm{p}<.01)$, intentions to get a specific grade $(\beta=.23, \mathrm{p}<.01)$, and intentions to quit studying $(\beta=.19, \mathrm{p}<.01)$ as significant independent predictors. The results provide support for hypothesis 1 which states that academic achievements as measured in grades are significantly predicted by individual variables. 


\subsection{Predicting actual grades with $L E$ variables}

The second regression analysis was also performed in which actual grades were regressed on social identity variables (step 1), components of OCB (step 2), perceived justice and learning climate (step 3), and sense of inclusion at (step 4). In the final regression equation, the predictors under consideration explained zero $\%(0 \%)$ of the variance in actual grades. None of the included variables emerged as significant in the final step of the regression analysis. The results do not provide support for hypothesis 2, which states that academic achievements as measured in grades are significantly predicted by LE variables. The results provide however support for hypothesis 3, that individual variables are better predictors of academic achievements as measured in grades, compared to LE variables.

\section{Discussion}

The results reveal that hypothesis one is supported. Thus, academic achievements as measured in grades are significantly predicted by individual variables. As implied in the introduction, this finding is expected considering that effects of individual variables used in the current study are well documented in previous research. However, hypothesis two is not supported by the present findings. The results show that the accumulated effect of LE variables on academic achievements as measured in grades is non-existent. Although we anticipated the predictive dominance of individual variables compared to LE variables (hypothesis three), the results reveal virtually no relation between college grades and contextual influence. Our anticipation was based on previous research suggesting that a supportive learning environment is important for high academic achievement (Wang \& Holcombe, 2010). The one possible explanation for this finding is that the effects of LE on academic achievement is indirect and mediated by the workings of individual dispositions. Support for this reasoning is visible in the descriptive analysis of the covariate positive relation between individual and LE variables. Thus, it is possible that LE variables set a basis or background for the development of individual processes that directly influence college grades. This would mean that LE variables nevertheless are important in the sense that they form a contextual setting that stimulates efforts and self-confidence in learners. The effects of positive LE are central to academic achievement, but they are channeled through the number of individual variables. 


\section{References}

Ajzen, I. (1991). The theory of planned behavior. Organizational Behavior \& Human Decision Processes, 50, 179-211.

Allison, B. J., Voss, R. S., \& Dryer, S. (2001). Student classroom and career success: The role of organizational citizenship behavior. Journal of Education for Business, 76, 282288.

Blader, S. L., \& Tyler, T. R. (2003). What constitutes fairness in work settings? A fourcomponent model of procedural justice. Human Resource Management Review, 13, 107-126.

Credé, M., Roch, S. G., \& Kieszczynka, U. M. (2010). Class attendance in college: A metaanalytic review of the relationship of class attendance with grades and student characteristics. Review of Educational Research, 80, 272-295.

Furrer, C. \& Skinner, E. (2003). Sense of relatedness as a factor in children's academic engagement and performance. Journal of Educational Psychology, 95 (1), 148-162.

Greenberg, J. (2010). Organizational justice: The dynamics of fairness in the workplace. In S. Zedeck (Ed.), APA handbook of industrial and organizational psychology (Vol. 3, pp. 271-327). Washington, D.C.: American Psychological Association

Harackiewicz, J. M., Barron, K. E., Tauer, J. M., \& Elliot, A. J. (2002). Predicting success in college: A longitudinal study of achievement goals and ability measures as predictors of interest and performance from freshman year through graduation. Journal of Educational Psychology, 94(3), 562.

Kovač, V. B., Cameron, D. L., \& Høigaard, R. (2016). The extended Theory of planned behavior and college grades: The role of cognitive and automatic processes in the prediction of student's Psychology, 36(4), 792-811.

Podsakoff, P. M., Ahearne, M., \&, MacKenzie, S. B. (1997). Organizational citizenship behavior and the quantity and quality of work group performance. Journal of Applied Psychology, 82, 262-270.

Richardson, M., Abraham, C., \& Bond, R. (2012). Psychological correlates of university students' academic performance: A systematic review and meta-analysis. Psychological Bulletin, 138, 353-387.

Samdal, O., Wold, B., \& Bronis, M. (1999). Relationship between students' perceptions of school environment, their satisfaction with school and perceived academic achievement: An international study. School Effectiveness and School Improvement, 10(3), 296-320.

Sharma, D., \& Silbereisen, R. K. (2007). Revisiting an era in Germany from the perspective of adolescents in mother headed single-parent families. International Journal of Psychology, 42, 46-58.

Verplanken, B., \& Orbell, S. (2003). Reflections on past behavior: A self-report index of habit strength. Journal of Applied Social Psychology, 33, 1313-1330.

Wang, M.-T., \& Holcombe, R. (2010). Adolescents' perceptions of school environment, engagement, and academic achievement in middle school. American Educational Research Journal, 47, 633-662. 